\title{
Continuum of one-sign solutions of one-dimensional Minkowski-curvature problem with nonlinear boundary conditions
}

\author{
Yanqiong $\mathrm{Lu}^{1}$ and Zhengqi Jing ${ }^{1}$ \\ ${ }^{1}$ Northwest Normal University
}

January 17, 2021

\begin{abstract}
In this work, we investigate the continuum of one-sign solutions of the nonlinear one-dimensional Minkowski-curvature equation $\$ \$-\backslash \operatorname{big}\left(u^{\prime} / \backslash \operatorname{sqrt}\{1-\backslash \text { kappa u'^} 2\} \backslash \text { big }\right)^{\prime}=\backslash$ lambda $\mathrm{f}(\mathrm{t}, \mathrm{u}), \backslash \backslash \mathrm{t} \backslash \mathrm{in}(0,1) \$ \$$ with nonlinear boundary conditions $\$ \mathrm{u}(0)=\backslash$ lambda $\mathrm{g}_{-}-$ $1(\mathrm{u}(0)), \mathrm{u}(1)=\backslash$ lambda $\mathrm{g}_{-} 2(\mathrm{u}(1)) \$$ by using unilateral global bifurcation techniques, where $\$ \backslash$ kappa $>0 \$$ is a constant, $\$ \backslash$ lambda $>0 \$$ is a parameter \$g_1,g_2:[0,\infty $) \backslash$ to $(0, \backslash$ infty $) \$$ are continuous functions and $\$$ f: $[0,1] \backslash$ times $[-\backslash$ frac $\{1\}\{\backslash$ sqrt $\{\backslash$ kappa $\}\}, \backslash$ frac $\{1\}\{\backslash$ sqrt $\{\backslash$ kappa $\}\}] \backslash$ to $\backslash$ is a continuous function. We prove the existence and multiplicity of one-sign solutions according to different asymptotic behaviors of nonlinearity near zero.
\end{abstract}

\section{Hosted file}

Lu and Jing's manuscript.pdf available at https://authorea.com/users/389882/articles/504407continuum-of-one-sign-solutions-of-one-dimensional-minkowski-curvature-problem-withnonlinear-boundary-conditions 